\title{
Influence of High-speed Railway Network Construction on Accessibility and Urban Spatial Pattern in Henan Province \\ Yuan Lu ${ }^{1, a,{ }^{*}}$, Peihong Chen ${ }^{2, b}$
}

${ }^{1}$ School of Economics and Management of Beijing Jiaotong University, Beijing, China

${ }^{2}$ School of Economics and Management of Beijing Jiaotong University, Beijing, China

a13849533259@163.com, bphchen@bjtu.edu.cn

*Yuan Lu

Keywords: High-speed railway, Accessibility, Urban spatial pattern.

\begin{abstract}
The opening of high-speed railway will have a significant impact on the accessibility level and economic development of cities along the line. Taking Henan province as an example, this paper analyzes the influence of the construction of high-speed rail network on the accessibility and economic potential of cities along the route by using the two indexes of average travel time and economic potential. The results show that the construction of high-speed railway network has improved the accessibility level and economic development potential of relevant cities in Henan province, and the polarization effect of Zhengzhou has been strengthened, and Henan province has gradually formed an economic belt along the high-speed railway line.
\end{abstract}

\section{高铁网构建对河南省可达性及城镇空间格局的影响 \\ 卢媛 ${ }^{1, a,{ }^{*}}$ ，陈佩虹 ${ }^{2, b}$ \\ 1北京交通大学经济管理学院经济系, 北京, 中国 \\ 2北京交通大学经济管理学院经济系, 北京, 中国 \\ a13849533259@163.com, bphchen@bjtu.edu.cn \\ *卢媛}

关键词：高速铁路；可达性；城镇空间格局

中文摘要. 高速铁路的开通对沿线城市的可达性水平、经济发展会产生重大影响。本文以河 南省为例, 采用平均旅行时间和经济潜力两个指标分析高铁网的构建对沿线城市可达性和经 济潜力的影响。结果表明高铁网的构建提升了河南省相关城市的可达性水平和经济发展潜力, 郑州市的极化效应增强, 省内逐渐形成沿高铁线路延伸的经济带。

\section{1. 引言}

一个地区经济的发展与地理空间格局的改变往往伴随着交通方式的进步与变革。交通系 统承载着人流、物流、信息流等因而全方位影响着区域经济运作。进入工业社会以来, 铁路 以其运量大、运价低和安全性高等优势在社会的经济活动中承担着重要作用。然而, 随着社 会发展阶段的进一步升级与产业结构的调整, 普通铁路的速度与容量逐渐从优势转变为制约 经济发展的瓶颈。高速铁路是交通运输领域的一次重大技术突破, 代表了铁路部门提供客运 
服务的重大变化, 不仅能够提供更快的速度, 舒适度也大大提高, 并且帮助释放铁路运输能 力，缓解货运供给能力紧张的局面。

现代区域经济的发展与空间格局的塑造已不单单取决于经济节点的空间距离, 时间距离 才是影响经济活动的更重要因素。由于速度是高速铁路最为重要的特征, 高速铁路的开通往 往会拓宽人流、资金流和信息流等要素的流动方向，加快其流动速度，在区域尺度上产生时 空收敛效应。区域内城市之间通达时间大大缩短，有助于加强彼此间的经济联系，促进产业 结构的升级与发展。高铁的开通运营对于区域内城市发展的作用机制始于城市可达性的变化, 因此研究高铁对于区域发展的影响离不开对可达性的量化与分析。

\section{2. 研究概述}

美国综合社会科学空间中心（CSISS）认为对于可达性概念和方法的分析是理解社会、 经济和政治观点的基础。学术上, 可达性通常用来描述位于交通网络中各个经济节点之间进 行相互作用的机会大小，其概念内涵丰富，具有多种类型的测算指标。常用于分析可达性变 化引致的时空效应的有平均旅行时间、加权旅行时间、日可达性和经济潜力等。这些指标侧 重方向各有不同，赋予了可达性空间意义、时间意义和社会经济意义。

近年来，国内外学者借助可达性模型分析高铁对于区域发展影响方面已有大量成果。国 外学者较为关注高铁引致的可达性变化带来的发展公平性问题。Andrés Monzón等（2013）基 于可达性指标研究了西班牙高铁的扩展对于其城市发展公平性的问题, 高铁的发展显然改善 了可达性水平，但是没有改变不同城市存在的差异性和优势地位情况，大型交通项目的政策 制定者需要更加权衡效率与公平问题; Hyojin Kim等（2015）利用加权旅行时间和经济潜力 指标对韩国高铁网络扩展各阶段的可达性进行测度, 并评价其空间分布和变化。研究结果表 明高铁发展各阶段的可达性影响不同，虽然每一次高铁扩建会改善更多城市的可达性情况， 但由于可达性的改善集中在靠近首尔的高铁沿线城市，空间公平性在2010-2011年的扩建中被 削弱了，未来高铁的扩建可能会重点改善偏远地区的可达性，提高空间公平性; Héctor S 等

（2012）从可达性角度考察了英国新建高铁，对其带来的区域可达性效益提出质疑，认为评 价任何一条高铁线路必须考虑更广泛的地理区域情况以及交通网络之间的集成。国内学者也 利用可达性模型对于高铁的发展做出了大量研究。郭鹏军等（2019）基于可达性选取平均旅 行时间、经济潜力、日可达性方法，测度发现高铁网开通后山西省沿线城市可达性、经济潜 力均有改善和提升，山西省“一核一圈三群”城镇空间格局日益成型，高铁网建设将为山西空 间经济格局演变及城镇体系框架构建提供基础支撑条件；孟德友等（2017）研究了河南“米” 字形高速铁路网的构建对各相关地市省内和省际可达性及城镇空间格局的影响，发现各地市 省内和省际可达性水平改善, 郑州的极化效应进一步增强, 边缘城市交通状况有所改善; 赵 威等 (2018) 借助时间距离测算模型、引力模型、经济潜能模型探讨郑徐-郑西高铁对沿线城 市可达性和空间格局的影响, 认为区域内空间经济格局呈现出由沿高铁延伸的经济发展轴和 以郑泫洛都市区、西渭都市区为重要经济发展区组成的“一轴两核”的发展趋势，郑州市的区 域核心地位显著增强; 姚胜永等 (2019) 将京石客运专线的7个站点城市按城市规模进行分类, 对比专线建成前和建成后的城市可达性，认为7个站点城市可达性均有提升，沿线“廊道效应” 有所增强，并且不同层次城市之间的差距减小，区域一体化趋势更加明显; 文霕等（2017） 从沿线城市加权旅行时间和中心城市“小时经济圈”两个方面分析高铁开通对中国城市可达性 的影响，发现高铁开通有效改善了沿线城市可达性，东中西三大区域的交通发展不均衡性有 小幅度改善。

回顾以往研究发现, 大多数学者从某条高铁线路出发, 研究其对沿线城市可达性的影响, 或是探讨既定区域内高铁网的建设对于区域内城市可达性以及空间经济格局的影响。本文重 点研究河南省内高铁网的建设对于站点城市省内可达性的影响, 基于此探讨河南省的城镇空 
间布局。河南省提出以郑州市为中心, 建立“米”字形高铁网, 已有学者对此进行研究, 本文 试图在新的时间框架下对此进行分析。

\section{3. 可达性测算指标}

\section{1 平均旅行时间}

平均旅行时间是度量城市可达性的方法之一，具体指在某区域内中心城市借助被研究交 通系统到达该区域内其他中心城市的最短旅行时间的平均值，其表达式通常为:

$$
A_{i}=\frac{1}{n} \sum_{i=1}^{n} T_{i j}
$$

表达式中， $A_{i}$ 为中心城市 $\mathrm{i}$ 的平均旅行时间， $A_{i}$ 值越小，平均旅行时间越短，表明该城市 可达性状况越好, 反之则越差; $T_{i j}$ 为中心城市 $\mathrm{i}$ 通过被研究交通系统到达中心城市 $\mathrm{j}$ 的最短时 间, 这里特指通过普速铁路或高速铁路的最短旅行时间; $\mathrm{n}$ 为该区域内除中心城市 $\mathrm{i}$ 以外的其 他城市数。

\section{2 经济潜力}

区域中的城市不是孤立存在的, 通常会受到其他城市的辐射带动作用。这种辐射带动作 用可以用经济潜力来表达, 潜力的大小与城市质量或规模成正比，与城市间空间距离或时间 距离成反比，具体表达式为:

$$
P_{i}=\sum_{j=1}^{n} \frac{M_{j}}{D_{i j}^{a}}
$$

表达式中， $P_{i}$ 表示中心城市 $\mathrm{i}$ 的经济潜力，即克服距离成本参与经济活动机会的大小; $M_{j}$ 表示中心城市 $\mathrm{j}$ 的城市质量或规模, 这里采用城市GDP和常住人口的几何平均值表示; $D_{i j}^{a}$ 表 示借助被研究交通系统从 $\mathrm{i}$ 城市到 $\mathrm{j}$ 城市的最短旅行时间, 这里特指通过普速铁路或高速铁路的 最短旅行时间; $\mathrm{a}$ 表示距离摩擦系数, 通常取值为 $1 ; n$ 为该区域内除中心城市 $\mathrm{i}$ 以外的其他城 市数。

\section{4. 河南省可达性分析}

\section{1 研究区域概况}

河南省位于中国中部，界于北纬 $31^{\circ} 23^{\prime}-36^{\circ} 22^{\prime}$ ，东经 $110^{\circ} 21^{\prime}-116^{\circ} 39^{\prime}$ 之间，东部与安徽、 山东相接, 北部与河北、山西相临, 西部为陕西, 南部为湖北, 总面积为 16.7 万平方千米, 素有“九州腹地、十省通唄”之称，是全国重要的综合交通枢纽和物流、人流和信息流集散中 心。截止2019年, 全省下辖 17 个省辖市、1 个省直管市、 21 个县级市、 85 个县、 53 个市辖区。 据统计。2018年全省GDP为 48055.86 亿元, 比上年增长 $7.6 \%$, 人均GDP达 50152 元, 增长 $7.2 \%$ 。 人口方面, 河南省历来是人口大省, 2018 年末常住人口为 9605 万人, 比上年末增加 46 万人, 常住人口城镇化率 $51.71 \%$ ，比上年末提高 1.55 个百分点。

河南省地理位置十分重要，具有望北向南、承东启西的作用。作为中国东部沿海地区与 中西部内陆地区的结合部, 是中国经济由东向西梯次推进发展的中间地带。河南省省会郑州 是中国重要的铁路枢纽城市, 京广铁路与陇海铁路两条交通大动脉在此交汇, 为城市发展带 来了机遇, 增强了郑州市经济辐射能力。随着中国迈入高速铁路时代, 河南省也推进了高铁 建设, 自2010年开始, 多条高速铁路沿途经过河南省, 为相关城市的发展注入经济活力。河 南省高速铁路开通情况具体见表1。《河南省铁路网规划研究报告(2013 2030)》指出要形成 
以京广、徐兰高铁组成的“十”字形，辅以郑渝、郑济、郑合和郑太高铁放射线的“米”字形客 运专线网。“米”字形高铁网中“一横”与“一坚”已全线通车运营, 其余部分也均在规划与建设 中。该高铁网的建设将与国家高铁网有机衔接, 形成以郑州为中心连南贯北、承东启西的高 速铁路大动脉，强化郑州市枢纽功能，有助于进一步提升河南的区位优势。

表1 河南省高速铁路开通详情

\begin{tabular}{|c|c|c|c|}
\hline \multirow{2}{*}{ 开通时间 } & \multicolumn{3}{|c|}{ 线路 } \\
\cline { 2 - 4 } & 名称 & 起始点 & 途经的河南省地级市 \\
\hline 2010 & 郑西客运专线 & 郑州, 西安 & 郑州、洛阳、三门峡 \\
\hline 2012 & 石武高速铁路 & 石家庄, 武汉 & $\begin{array}{l}\text { 安阳、鹤壁、新乡、郑州、 } \\
\text { 许昌、漯河、驻马店、信阳 }\end{array}$ \\
\hline 2016 & 郑徐高速铁路 & 郑州, 徐州 & 郑州、开封、商丘 \\
\hline
\end{tabular}

\section{2 数据来源}

河南省2010年首次通高铁，本文选择2008年和2018年作为有无高铁的可达性对比年份。 2008年相关旅行时间数据主要来源于石开旅行时刻表软件，2018年相关旅行时间数据来源于 铁路官方网站。

研究对象为河南省省内通高铁的 12 个地级市, 分别为: 郑州、洛阳、三门峡、安阳、鹤 壁、新乡、许昌、漯河、驻马店、信阳、开封、商丘。2008年城市经济统计数据来源于 2009 年河南省统计年鉴, 2018年经济统计数据来自于各地级市2018年统计公报。

\section{3 平均旅行时间及经济潜力分析}

\subsection{1 高铁建设对河南省省内平均旅行时间的影响}

高铁网的建设提高了该 12 个地级市可达性水平, 郑州的极化作用进一步加强。如表 2 所示, 2008 年未通高铁时平均旅行时间均值为 2.7 小时, 可达性水平优于平均值的有郑州、安阳、新 乡、许昌、漯河、驻马店、开封。总体来说, 位于河南省腹地以及北部的地级市铁路交通状 况较好, 而位于东部的商丘、南部的信阳以及西北部的洛阳、三门峡可达性状况较差。2018 年高铁网部分形成后平均旅行时间均值为 1.24 小时, 较 2008 年提升了 $54 \%$, 各个地级市可达性 也均有不同水平的提升。2018年可达性水平优于平均值的有郑州、洛阳（平均旅行时间与均 值一致）、新乡、许昌、漯河、驻马店, 主要得益于郑西客运专线和石武高速铁路的开通。 可达性较差的三门峡和商丘均位于河南省边界区域, 与其他地级市距离较远, 省内可达性受 地理因素影响表现较差, 然而在对省外联系时, 门户区位优势显著。

表2 2008，2018年河南省12个地级市平均旅行时间

\begin{tabular}{|c|c|c|c|}
\hline \multirow{2}{*}{ 城市 } & \multicolumn{3}{|c|}{ 平均旅行时间/ $\mathrm{h}$} \\
\cline { 2 - 4 } & 2008 年 & 2018 年 & 增长率 \\
\hline 郑州 & 1.19 & 0.65 & $45 \%$ \\
\hline 洛阳 & 2.80 & 1.24 & $56 \%$ \\
\hline 三门峡 & 4.26 & 1.77 & $58 \%$ \\
\hline 安阳 & 2.60 & 1.30 & $50 \%$ \\
\hline 鹤壁 & 2.95 & 1.36 & $54 \%$ \\
\hline 新乡 & 2.20 & 0.98 & $55 \%$ \\
\hline 许昌 & 1.95 & 0.90 & $54 \%$ \\
\hline 漯河 & 2.15 & 1.02 & $52 \%$ \\
\hline 驻马店 & 2.63 & 1.20 & $54 \%$ \\
\hline 信阳 & 3.43 & 1.57 & $54 \%$ \\
\hline 开封 & 2.47 & 1.30 & $47 \%$ \\
\hline 商丘 & 3.77 & 1.61 & $57 \%$ \\
\hline 均值 & 2.70 & 1.24 & $54 \%$ \\
\hline
\end{tabular}




\subsection{2 高铁建设对河南省省内经济潜力的影响}

高铁网的建设提高了该 12 个地级市的经济潜力，城市间辐射带动作用增强。如表 3 所示， 2008年未开通高铁时, 经济潜力平均值为 5397.91。高于这一均值的城市有郑州、新乡、许昌、 漯河、驻马店、开封, 大多位于河南省腹地地区, 经济辐射作用较强。2018年高铁网部分形 成后各地级市均有大幅度增长。首先经济潜力均值达到了 17112.72 , 增长率达 $217 \%$ 。2018年 经济潜力高于这一均值的城市有郑州、鹤壁、新乡、许昌、漯河、开封。与 2008 年相比，鹤 壁经济潜力提升到了均值以上, 而驻马店经济潜力 2018 年低于均值。这两个地级市均属于石 武高速铁路沿线城市, 而从地理条件看, 鹤壁距离新乡、郑州、开封等城市较近, 经济互动 更便利，更容易受到辐射带动作用。经济潜力虽有提升但在2018年同时间与其他城市相比较 弱的城市有洛阳、三门峡、安阳、信阳和商丘。这些城市大多位于河南省边界地区, 地理位 置在一定程度上限制了经济潜力的提升。

表3 2008，2018年河南省12个地级市经济潜力

\begin{tabular}{|c|c|c|c|}
\hline \multirow{2}{*}{ 城市 } & \multicolumn{3}{|c|}{ 经济潜力 } \\
\cline { 2 - 4 } & 2008 年 & 2018 年 & 增长率 \\
\hline 郑州 & 7857.45 & 20812.71 & $165 \%$ \\
\hline 洛阳 & 3263.00 & 13282.58 & $307 \%$ \\
\hline 三门峡 & 2500.10 & 11402.26 & $356 \%$ \\
\hline 安阳 & 4328.64 & 14900.27 & $244 \%$ \\
\hline 鹤壁 & 5273.88 & 21425.78 & $306 \%$ \\
\hline 新乡 & 5770.69 & 21444.84 & $272 \%$ \\
\hline 许昌 & 7089.81 & 21785.08 & $207 \%$ \\
\hline 漯河 & 8064.00 & 21732.14 & $169 \%$ \\
\hline 驻马店 & 5553.24 & 16148.61 & $191 \%$ \\
\hline 信阳 & 4937.43 & 11787.28 & $139 \%$ \\
\hline 开封 & 6723.58 & 19775.29 & $194 \%$ \\
\hline 商丘 & 3413.05 & 10855.85 & $218 \%$ \\
\hline 均值 & 5397.91 & 17112.72 & $217 \%$ \\
\hline
\end{tabular}

\section{5. 结论}

高铁网的构建提升了相关城市的可达性水平。12个地级市平均旅行时间全部降至 2 小时以 下，郑州为 0.65 小时，省会枢纽作用进一步加强。可达性的提升促进了劳动力、信息、资金 等生产要素的流动，增加了经济活跃度。高速铁路带来的时空收敛效应能够帮助促进城市实 现产业升级和经济发展，沿线城市应结合自身资源优势，合理布局产业发展，充分利用高铁 带来的区位优势。

高铁网的构建增加了相关城市的经济潜力。鹤壁、新乡、许昌和漯河经济潜力最为优越, 连同省会郑州，5个城市基本位于河南省中轴线上，形成一条发展条件极佳的河南省省内高铁 经济带。这些城市辐射作用增强，将会带动周边县市发展，增加其产业承接和商业投资机会。 周边县市应主动加强与高铁沿线城市联系，制定符合实际的发展战略，走具有自身特色的发 展道路。

《中原经济区规划（2012 2020年）》提出要提升郑州区域中心服务功能，推动多层次高 效便捷快速通道建设，促进郑州、开封、洛阳、平顶山、新乡、焦作、许昌、漯河、济源 9 市经济社会融合发展, 形成高效率、高品质的组合型城市地区和中原经济区发展的核心区域, 引领辐射带动整个区域发展。目前的“十”字形高铁网发展态势良好，对中原城市群形成合理 的空间经济格局发挥了关键作用，同时也为全省未来“米”字形高铁网建成，以郑州市为中心 
呈放射状发展奠定了基础, 具体如何依托“米”字形高铁网寻求合理构建城镇空间经济格局需 要进一步理论与实践的双重创新。

\section{致谢}

本文为国家社科基金一般项目《我国高速铁路建设项目经济评价体系重构研究》(批准号 18BJY170)的阶段性成果之一。

\section{References}

[1] Andrés Monzón, Ortega E, Elena López, Efficiency and spatial equity impacts of high-speed rail extensions in urban areas, Cities, vol.30, pp. 18-30, 2013.

[2] Kim H, Sultana S, The Impacts of High-speed rail extensions on accessibility and spatial equity changes in South Korea from 2004-2018, Journal of Transport Geography, vol. 45, pp. 48-61, 2015.

[3] Martínez Sánchez-Mateos, Héctor S, Givoni M, The accessibility impact of a new High-Speed Rail line in the UK-a preliminary analysis of winners and losers, Journal of Transport Geography, vol. 25, pp. 105-114, 2012.

[4] GUO Pengjun, LIU Hailong, XIAO Jie, NIU Juan, MA Yanhong, Impact of High-speed Rail on Accessibility, Economy Potential and Urban Spatial Pattern in Shanxi Province, Journal of Hebei Normal University, vol. 43, pp. 166-177, 2019.

[5] JIANG Bo, CHU Nanchen, LI Yun, CHEN Yan, SHEN Baorong, XUE Rui, LI Zirui, Accessibility of High-Speed Railway and Land Value: Literature Review and Prospect, Economic Geography, vol. 39, pp. 9-13, 2019.

[6] LI Tao, MA Wei, GAO Xingchuan, CAO Xiaoshu, Evaluating the Impacts of the Xiamen-Shenzhen High-Speed Railways on Accessibility and Its Differentiation: A Super-DEA Approach, Economic Geography, vol. 37, pp. 67-76, 2017.

[7] LIU Zhihong, WANG Lihui, Study on Regional Economic Effect and Influence Mechanism of Transportation Infrastructure-Evidence From the Line of Zhengzhou-Xi'an High-speed Railway, Economic Science, vol. 2, pp. 32-46, 2017.

[8] MENG Deyou, WEI Ling, FAN Xinsheng, GAO Chao, "Star-type" High-speed Railway Network and Its Impacts on the Accessibility and Urban Spatial Patter in Henan, China, Geographical Science, vol. 37, pp. 850-858, 2017.

[9] WEN Hu, HAN Xu, THE IMPACTS OF HIGH-SPEED RAILS ON THE ACCESSIBILITY AND THE SPATIAL PATTERN OF REGIONAL ECONOMIC DEVELOPMENT IN CHINA, Human Geography, vol. 32, pp. 99-108, 2017.

[10]ZHANG Li, ZHU Changning, CAO Lina, Study on Influence of Shanghai-Nanjing Inter-city High-speed Railway on Regional Accessibility, Railway Transportation and Economy, vol.35, pp. 82-87, 2013.

[11]ZHAO Wei and LI Zhengyang, Study on the Influence of High-speed Railways on the Accessibility and Spatial Economic Pattern of Cities along the Lines-Taking Zhengzhou-Xuzhou and Zhengzhou-Xi' an High-speed Railway as Examples, Journal of Henan University, vol. 48, pp. 45-53, 2018. 